\title{
Design of Neural Net to Detect Early Stage of Fire and Evaluation by Using Real Sensors' Data
}

YOSHIAKI OKAYAMA, TAKASHI ITO and TORU SASAKI

Nohmi Bosai LTD, Chiyoda-ku, Tokyo 102, Japan

\section{Abstract}

Sensitive fire sensors are necessary to detect fires in their early stage, but they often produce false alarms from non-fire phenomena. It has lately became clear that fire and non-fire patterns exist as a result of analyzing fire and non-fire testing data. Changing the rate of sensor output per minute and normalized sensor output are used as patterns for analyzing sensors' data in various condition.

An odor sensor and a smoke sensor are very effective in discriminating between fire / non-fire phenomena by adopting artificial neural net which has been trained to recognize their patterns.

Key words : odor sensor, $\mathrm{SnO}_{2}$ sensor, smoke sensor, neural net, fire detection

\section{Introduction}

The idea that fire detection in very early stage is essential to protect human life and property has become common. Especially, if a fire occurs, in computer room and expensive electronic apparatus, the fire damage is very large. It is important to detect abnormal environment by sensors before smoke spreads too far. Recently extensive studies on odor sensor and neural net have been made.1-3) An odor sensor is capable of smelling an odor before the onset of smoking from heated materials. The author's studies in two odor sensors having $\mathrm{SnO}_{2}$ film layers of different thickness was useful for the discrimination between different odors. The position of their output on $\mathrm{X}$ and $\mathrm{Y}$ axes could be assigned to a specific area by odor group.

In this study, an investigation was made as to whether the combination of an odor sensor and a smoke sensor would be effective in different fires in their early stages and discriminate between fires and non-fire phenomena. While in previous study (4), only sensor' output level had been used, in this study the normalized sensors' level and time-series sensors data were prepared for a neural net to discriminate fires.

The neural net which has been trained to recognize many sensors' patterns is capable of detecting early stage of fires and discriminat- 


\section{Extraction of sensors' behavior to fires and non-fire phenomena}

As fire sensors to detect early stage of fires, two kinds of sensors e.g.odor sensor and very sensitive smoke sensor were chosen. The odor sensor was made of $\mathrm{SnO}_{2}$ thin film (1600 A) which was deposited on an alumina substrate, and its operation temperature was $300 \mathrm{C}$. The very sensitive smoke sensor operated on the light-scattering principal .

The reason was that an odor sensor is very sensitive to burning odor and a very sensitive smoke sensor is capable of responding to such thin smoke as $0.01 \% / \mathrm{m}$, which is not visible. The sensors were set up to analyze environmental data in places such as an office, a hall and a dinning room.

The sensors' data were logged and the specific characteristics of data were extracted. The measuring circuit of the odor sensor is shown in Fig.1. As regards data of fire tests, sensors' characteristics were picked out when various materials smouldered in different distance between the fire source and sensors. Sensors' data measured in various environment and fire tests are classified in Table 1.

One datum of sensors was divided into two data e.g. normalized sensor level and rate of change per minute. This classification of data is useful for discrimination between a fire and a non-fire because judging elements

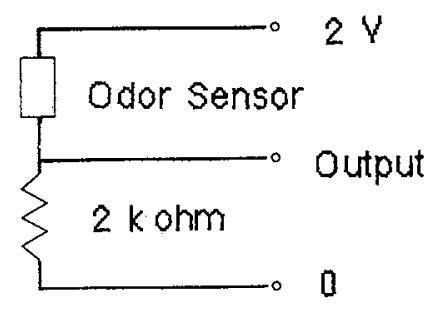

Fig.1 Measuring circuit of odor sensor were taken not only sensor level but time-series data e.g. rate of change of sensor level per minute.

\section{Design of Neural Net for Fire Detection}

It is reported that a neural net is very effective to make a firedecision(1). The data in Table 1 was well suited for adopting a neural net because the sensor data were normalized up to 1.0 value as dynamic range. The neural net has three layers e.g. input ,hidden and output layers(Fig.2). The number of the input layer's and hidden layer's neuron was four each . The output layer had one neuron. Fire probability value was determined as follows.

The value of fire probability was assigned to 0.99 when sensor was 
installed above fire source, and 0.95 at three meters distant from the fire source. Fire probability value was 0.75 that was minimum in fire cases. The neural net learned the definition table having sixteen definition patterns.

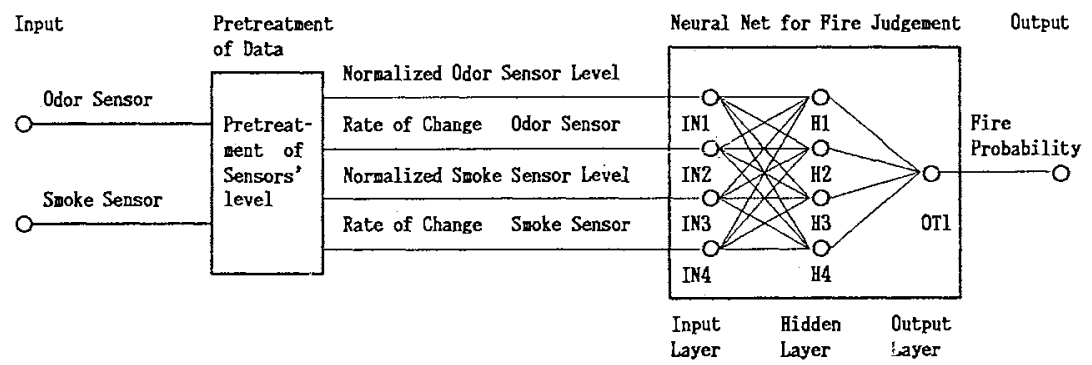

\section{Fig .2 Structure of Neural Net}

The combination between neurons was converted to the value of the weighted strings. After the neural learned the defined Table 1 , it can make a fire-decision based on the sensor data.

The difference between definition values and calculated ones became closer as the net computed more times.

\section{Evaluation of Neural Net by Real Sensor Data}

An investigation was made to confirm that the learnt neural net worked effectively to make a fire-decision by using real sensor data.

Six experimental data sets were given to the neural net of which four cases were environment data and two cases were fire test data. Fig. 3 shows the environmental data. The probability of fire reaches a maximum of 0.2 . The smoke sensor's level started to fluctuate but the odor sensor' level rose slightly with cooking as shown in Fig.4. In this case the neural net can not make a fire-decision because the trend of sensor level seemed to indicate a genuine fire. The resulting probability value was almost alarm level(0.75).

On the other hand, if only odor sensor' output became high but the smoke sensor remained low level in Fig.5, the fire probability 
Table 1 Sensor Data in Fires and Non-fire Phenomena

\begin{tabular}{|l|l|l|l|l|}
\hline & \multicolumn{2}{|l|}{$\begin{array}{l}\text { Normalized } \\
\text { Data }\end{array}$} & \multicolumn{2}{l|}{ Rate of Change } \\
\hline Conditon & $\begin{array}{l}\text { Odor } \\
\text { Sensor }\end{array}$ & $\begin{array}{l}\text { Snoke } \\
\text { Sensor }\end{array}$ & $\begin{array}{l}\text { Odor } \\
\text { Sensor }\end{array}$ & $\begin{array}{l}\text { Smoke } \\
\text { Sensor }\end{array}$ \\
\hline Unmanned & 0.037 & 0.080 & 0.015 & 0.009 \\
\hline Unmanned & 0.027 & 0.080 & 0.006 & 0.012 \\
\hline Non-fire & 0.255 & 0.150 & 0.079 & 0.039 \\
\hline Non-fire & 0.388 & 0.184 & 0.122 & 0.094 \\
\hline Non-fire & 0.167 & 0.652 & 0.146 & 0.603 \\
\hline Non-fire & 0.193 & 0.167 & 0.058 & 0.096 \\
\hline Non-fire & 0.538 & 0.295 & 0.080 & 0.305 \\
\hline Hon-fire & 0.744 & 0.066 & 0.586 & 0.008 \\
\hline Non-fire & 0.170 & 0.100 & -0.100 & 0.000 \\
\hline Fire Test & 0.465 & 0.211 & 0.077 & 0.131 \\
\hline Fire Test & 0.442 & 1.000 & 0.405 & 1.000 \\
\hline Fire Test & 0.956 & 1.000 & 0.786 & 1.000 \\
\hline Fire Test & 0.702 & 0.506 & 0.160 & 0.230 \\
\hline Fire Test & 0.304 & 1.000 & 0.535 & 1.000 \\
\hline Fire Test & 0.965 & 1.000 & 0.898 & 1.000 \\
\hline Fire Test & 0.956 & 1.000 & 0.786 & 1.000 \\
\hline
\end{tabular}

\begin{tabular}{|l|l|}
\hline \multicolumn{2}{|c|}{ Fire Probability } \\
\hline Defined & $\begin{array}{l}\text { Calucul- } \\
\text { ated }\end{array}$ \\
\hline 0.000 & 0.039 \\
\hline 0.000 & 0.035 \\
\hline 0.050 & 0.090 \\
\hline 0.200 & 0.271 \\
\hline 0.250 & 0.248 \\
\hline 0.100 & 0.048 \\
\hline 0.250 & 0.255 \\
\hline 0.100 & 0.067 \\
\hline 0.150 & 0.161 \\
\hline 0.750 & 0.697 \\
\hline 0.750 & 0.745 \\
\hline 0.990 & 0.994 \\
\hline 0.900 & 0.937 \\
\hline 0.850 & 0.980 \\
\hline 0.950 & 0.987 \\
\hline 0.980 & 0.994 \\
\hline
\end{tabular}


became 0.15 initially, but it was depressed to a low value because of decreasing false alarm when there aroma of coffee existed ,not smoke. The case of smoking was investigated in Fig. 6 . The smoke sensor's level was like spike noise and that got moderately high. The fire probability remained low and that could not reach prealarm 1 level (0.25). The odor sensor is not as sensitive to the odor of smoking as that of smouldering. The authors assume that the temperature of the smoke was so high from the oxidation of a lighted cigarette that the odor due to burning was decreased.

A beechwood chip experiment was used to investigate the difference of output of sensors located at different distances from the fire source i.e. two meters and five meters. The weight of beech wood in each experiment was only $1.5 \mathrm{~g}$. The room volume was $270 \mathrm{~m}^{3}$ : $10(\mathrm{w}) \times 10(\mathrm{~L}) \times 2.7(\mathrm{H}) \mathrm{m}$. In the case two meters between the fire source and the sensors as shown in Fig.7, the smoke sensor's output increased rapidly in ten minutes and fluctuated, thus the deviation of fire probability was

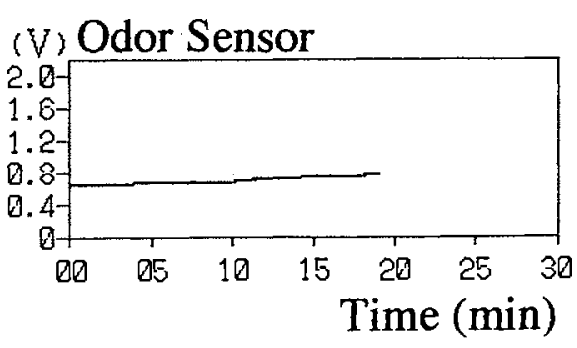
was large. In Table1, the fire probability was remained small when the slope of the sensor's output was negative despite its high level. In case of three meters distance in Fig.8, the fire probability surpassed the alarm level $(0.75)$. The smoke sensor's output increased without fluctuation.

The rising time of sensor's output was late at flve minutes, as in case of two meters distance.
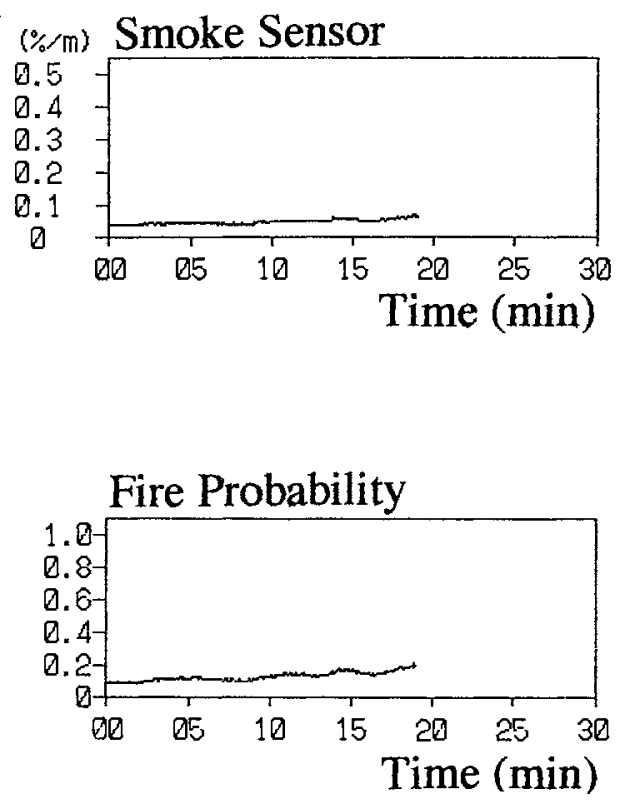

Fig.3 Normal Environmental Data 

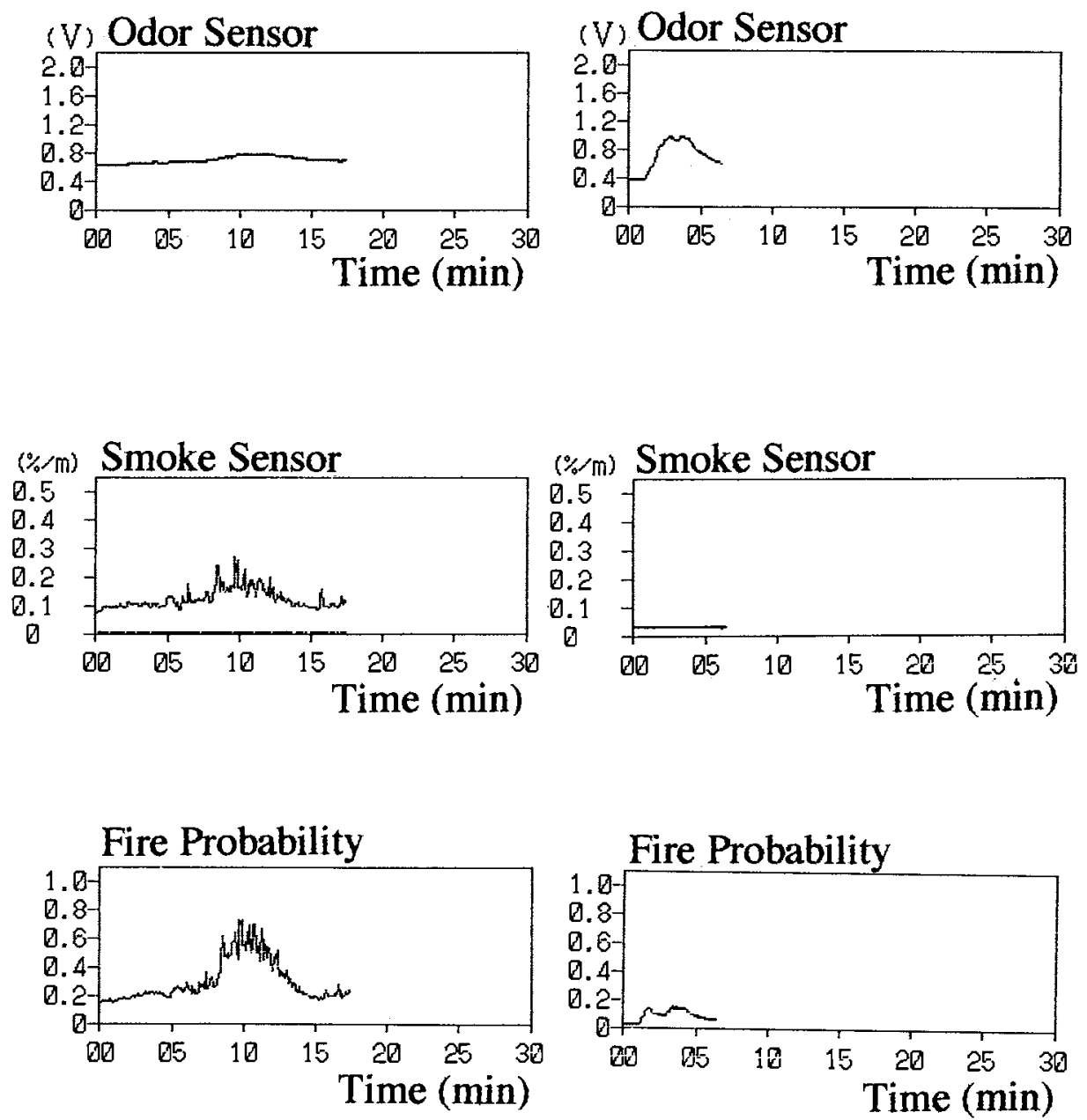

Fig.4 Cooking Case

Fig.5 Coffee Aroma 
(v) Odor Sensor

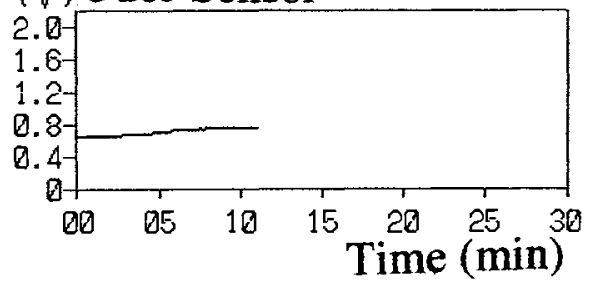

(v) Odor Sensor

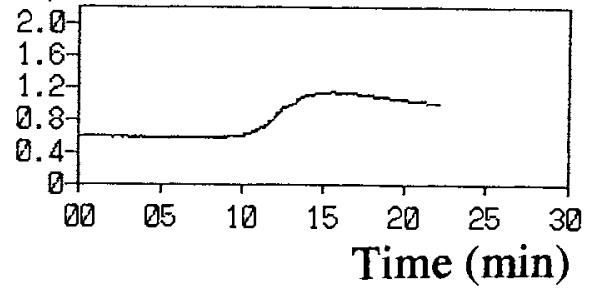

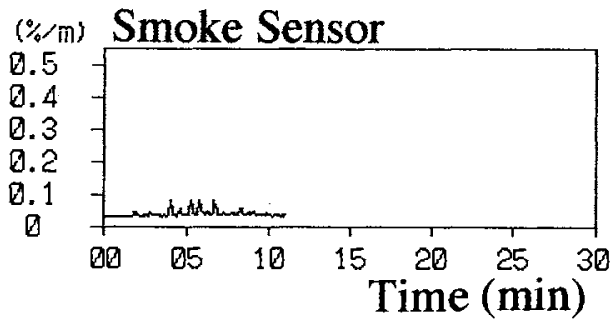

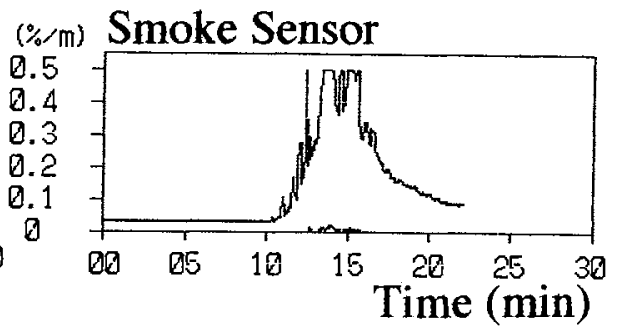

Fire Probability

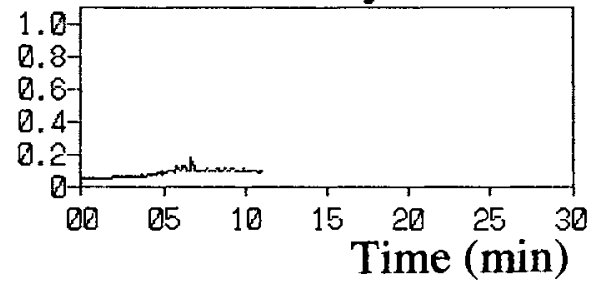

Fig.6 Smoking Case

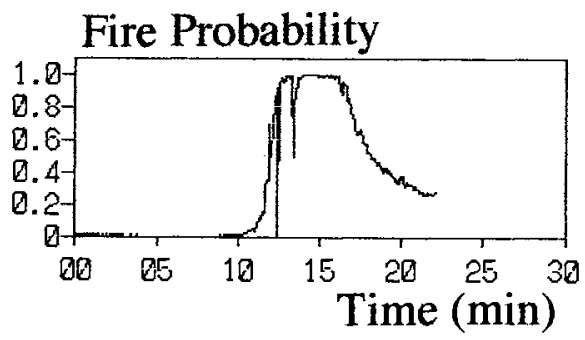

Fig.7 Beechwood

Smouldering

(sensors were installed $2 \mathrm{~m}$ away from the fire source) 

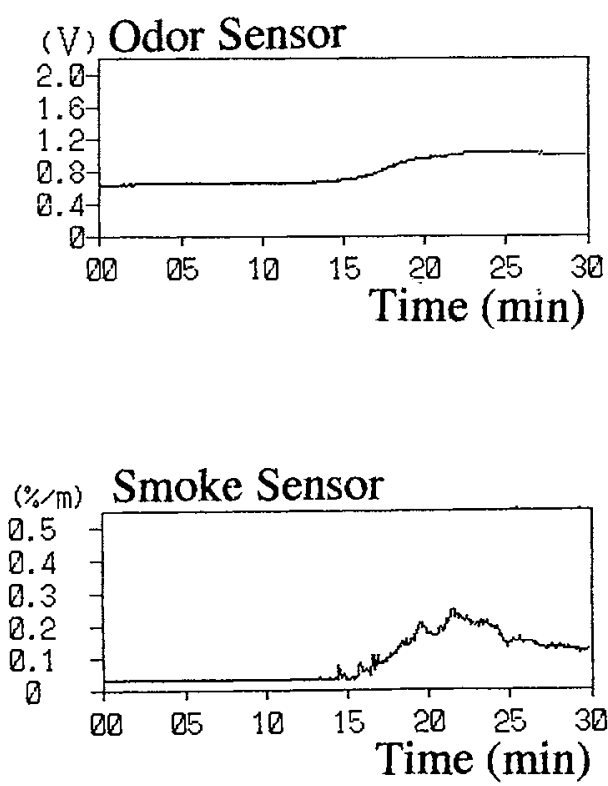

Fire Probability

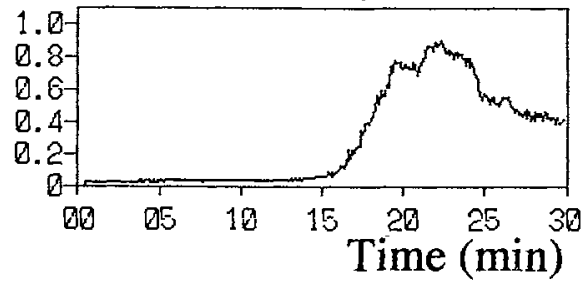

\section{Fig.8 Beechwood Smouldering}

(sensors were installed $3 \mathrm{~m}$ away from the fire source)

\section{Conclusions}

(a) The flre decisions were quite reasonable when the environmental and the fire test data were given to the neural net.

(b) The fire decision in the fluctuating environment was not so reliable that in the stable condition because the trends of sensor's output were almost the same as fire phenomena. 


\section{References}

1)Y.Okayama,"A primitive study on fire detection by artificial neural net." proc. of the 9 th int. conf. on automatic fire detection(AUBE'89),pp.409-432, 1989 (Duisberg)

2)D.E.Rumelhart, G.E.Hint, and R.J.Williams, Learning internal representation by error propagation, "parallel distributed processing :Exploration in the micro structure of cognition,"vol.1, foundation MIT press,Boston, 1986

3)T.Nakamoto and H.Morilizumi ,"Odor sensor using quartz-resonator array and neural network pattern recognition,"proc. of the autumn conf. of inst. of Electric Engineering of Japan ,C-2, 1988

4)Y.Okayama ,"Approach to detection of fires in their very early stage by odor sensors and neural net "proc. of the 3rd int. symp. of Fire safety science, pp.955-964, 1991 
